\title{
Extended Spectrum Use of Percutaneous Transforaminal Endoscopic Decompression for Managing Patient with Cauda Equina Syndrome Due to Upper Lumbar Disc Herniation: A Case Report
}

\author{
Vaishali Waindeskar ${ }^{1}$, Anuj Jain ${ }^{2}$, Sunaina Tejpal ${ }^{2}$ and Charan Raj ${ }^{3 *}$ \\ ${ }^{1}$ Professor, Department of Anaesthesiology, AIIMS, Bhopal, India \\ ${ }^{2}$ Associate Professor, Department of Anaesthesiology AIIMS, Bhopal, India \\ ${ }^{3}$ Senior Resident, Department of Trauma and Emergency Medicine, AIIMS, Bhopal, \\ India
}

*Corresponding Author: Charan Raj, Senior Resident, Department of Trauma and Emergency Medicine, AIIMS, Bhopal, India.
Received: October 25, 2021

Published: December 07, 2021

(C) All rights are reserved by Charan Raj., et al.

\begin{abstract}
Cauda Equina, though a rare syndrome, but needs immediate intervention to get a successful outcome. Open surgical techniques like microdiscectomy and lumbar disc decompression and laminectomy combined with facetectomy for patients with Cauda Equina Syndrome (CES). General anesthesia requires all these surgical procedures with extensive bone and soft-tissue handling, resulting in spine instability. We presented a case of low back and severe leg pain with neurological deficit. We diagnosed as Cauda Equina Syndrome, managed successfully with Percutaneous Transforaminal Endoscopic Discectomy (PTED) under local anesthesia in the awake and aware patient. This approach avoids complications associated with general anesthesia.

Managing such cases with the percutaneous transforaminal endoscopic approach at the upper lumbar level has not been described in the literature.
\end{abstract}

Keywords: Cauda Equina Syndrome; Transforaminal Endoscopy; Disc Herniation; Low

\section{Back pain}

Glossary of terms: Percutaneous Transforaminal Endoscopic Discectomy (PTED), Cauda Equina Syndrome (CES).

\section{Introduction}

Low back pain is a common problem among the young to elderly age population leading to a low quality of life and fewer working days [1]. The lifetime incidence and prevalence of low back pain is nearly $15-30 \%$. There is usually a delay in diagnosing CES due to its varied clinical presentation and treatment. It is often delayed due to the patient's lower preference of choosing the surgical option as the first option for managing these cases. The usual treatment of CES is open lumbar disc decompression and laminectomy.
Due to high technical demand, discectomy using transforaminal endoscopic approach is considered skilled and experienced-based individualized surgery. Discectomy using interlaminar or transforaminal endoscopic approach is now being done by experts in endoscopic spine surgery across the globe due to high patient acceptance, better rehabilitation, faster recovery, good cosmetic reason, short hospital stay, and minimal complication with almost no neural damage.

\section{Case Summary}

A 32-year male patient presented to our institute with severe low back pain and lower limb weakness for 3 days. The patient also gives a history of bladder bowel involvement for the same dura- 
Extended Spectrum Use of Percutaneous Transforaminal Endoscopic Decompression for Managing Patient with Cauda Equina Syndrome Due to Upper Lumbar Disc Herniation: A Case Report

tion. Xray was advised to him, which shows herniation at L1/2 level (Figure 1). He was recommended for immediate decompression by open surgery, but the patient was not willing for open spine surgery and showed willingness for endoscopic surgery. Planning of transforaminal endoscopic surgery for the level above L3 requires an MRI Lumbar spine and sometimes a CT scan to mark the trajectory of the needle and endoscope. Due to the proximity of the kidney and other retroperitoneal structures [2], so endoscopic surgery was planned with informed written consent that if we could not decompress the spine completely, he has to go for open spine surgery later. We explained the procedure to the patient.

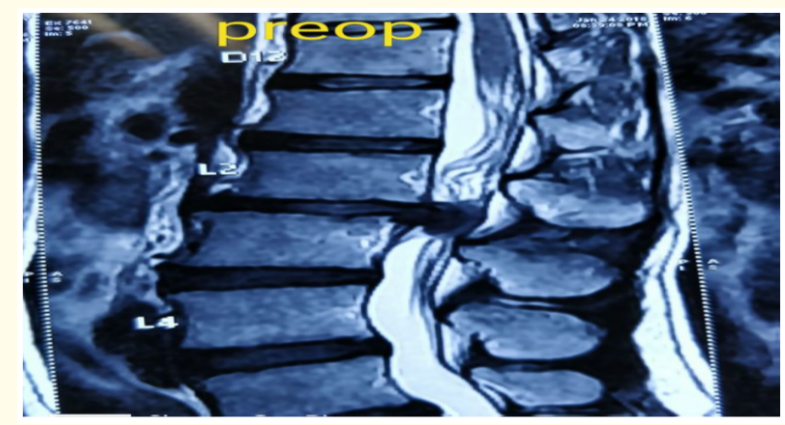

Figure 1: MRI Sagittal view showing Disc extrusion at L2/3 space with crowding of cauda equna.

In theater monitors attached, iv line secured and gave iv Midazolam $2 \mathrm{mg}$ and fentanyl 50 micrograms. The patient was positioned prone and cleaned the lumber area aseptically with betadine solution. 1\% lignocaine injected at the skin endpoint after proper marking done under $\mathrm{C}$ arm guidance. The needle was advanced in lumbar L1/2 disc space in Antero-posterior and Lateral view under fluoroscopy. We use the Wolf endoscope system for the procedure. TFED at L1/2 level and two massive fragments removed via transforaminal approach (Figure 2). The cannula was moved to epidural space, and free dura pulsations and traversing root was appreciated (Figure 3). The skin was closed with a single surgical stapler. Immediately after surgery, the patient reported excellent pain relief, and his motor power also reverted to normal (5/5) in the next two days. Postoperative MRI of the Lumbar spine showed adequate decompression of herniated fragment, with no recurrent herniation (Figure 4). At six months of follow-up, the patient experienced complete pain relief and full neurological recovery.

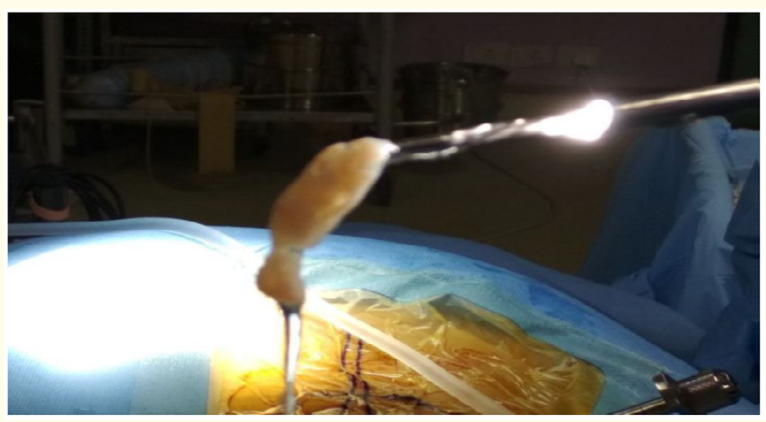

Figure 2: Extruded disc herniation removed endoscopically in a single piece

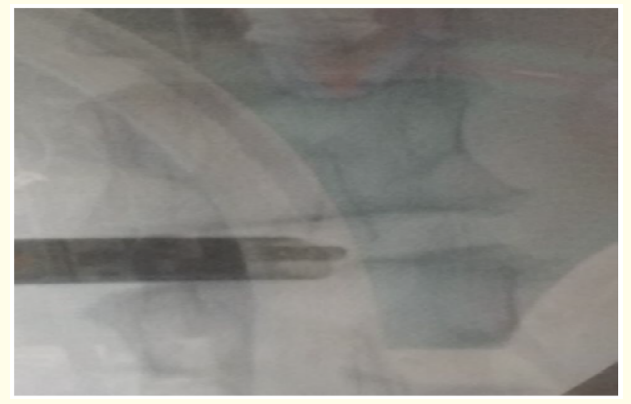

Figure 3: Cannula and disc rongeur under fluoroscopic AP view.

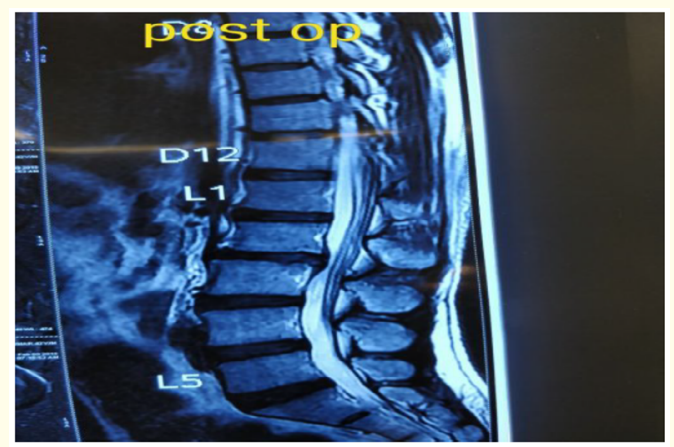

Figure 4: Postoperative MRI scan in sagittal view showing complete decompression of the spine and no pressure on the cauda equina roots. 


\section{Discussion}

Low back pain and leg pain is a major cause of disability across the world. Conservative management using drugs, physiotherapy, psychotherapy, acupuncture, and yoga remains the first-line treatment of low back pain due to disc herniation. Minimally invasive interventions include percutaneous methods including Stryker disc decompression, nucleoplasty, radiofrequency ablation, transforaminal endoscopic disc decompression.

Microdiscectomy, interlaminar endoscopic decompression, open disc decompression, or sometimes disc decompression and fixation are needed for back pain and neurological deficit [3]. Percutaneous decompression using transforaminal technique under local anesthesia is as effective as microdiscectomy for managing disc herniation (both protruded and extruded disc) [4].

CES occurs following sizeable central disc herniation or sequestration. Patients with this condition present with severe back and leg pain, neurological deficit including sudden onset weakness of lower limb, paralysis, foot drop, loss of sensation across the saddle and genital area, urinary retention, bowel, and sexual dysfunction [4]. The incidence of cauda equine syndrome varies from 1 in 33000 to 1 in 100000 , and it comprises around 2-6\% of lumbar disc surgery $[5,6]$.

There is a controversy between surgical decompression and neurological recovery timing and varied from 48 to 72 hours. Ahn., et al. in 322 cauda equine patients shown preoperative rectal dysfunction associated with worsened outcome [7]. Our patient had both bladder and bowel dysfunction, which improved after disc decompression. Our patient reported excellent pain relief and good neurological recovery within two days, which also proves the chemical washout response to irrigation used for endoscopic procedures and the structural component by percutaneous decompression [8].

In our experience, TFED facilitates the engagement of the working cannula through the Kambin's triangle into the disc, allowing the tip of the sleeve just near to herniated fragment of the disc. Although this technique is widely used worldwide for disc protrusion, extruded disc, and migrated disc, it has not used for cauda equine cases due to upper lumbar massive disc herniation.

Xiaolong., et al. described interlaminar endoscopic discectomy for L5/S1 central canal stenosis and extruded disc. He concluded that he could approach herniated disc through an interlaminar endoscopic approach [9]. Rapid recovery after percutaneous endoscopic decompression can explain that this surgery is done under local anesthesia, thus avoiding complications associated with general anesthesia. There is also chemical washout during endoscopic surgery as there is continuous irrigation with normal saline throughout the surgical procedure.

In our patient, the distance from the spine's midline to the entry point was $7.5 \mathrm{~cm}$. It is also necessary to keep the angle too shallow to avoid injury to retroperitoneal structures. In this patient, we were able to use the inside-out technique. Disc fragment was pulled out through the sleeve using disc forceps $2.5 \mathrm{~mm}$. The piece's kept tail held with the rongeur and took out a single big chunk of the herniated disc. The patient immediately became completely painfree and complete neurological recovery in the next two days.

There is massive literature regarding the timing of surgery and clinical presentation. Most of these studies recommend opting for surgical decompression for cauda equine syndrome cases as early as possible, usually within 24-72 hours [10]. In other cases, where time exceeds 72 hours, there remains a neurological deficit even after sufficient decompression. This endoscopic technique use as an emergency intervention/procedure. In the follow-up of 16 months for 20 cauda equina diagnosed patients, Hussain., et al. reported no difference between urgently operated patients versus patients operated within 24 hour.

Advances in technology and fine instruments have now a day's widened the horizon of endoscopic spine surgery with less failure and rapid patient outcome.

\section{Conclusion}

Cauda Equina Syndrome is very devastating not only to the patient but also to family with unpleasant clinical and legal squeals. Percutaneous TFED offers a truly minimal invasive option for patients with low back pain, radicular pain, and cauda equine syndrome patients with minimal tissue damage, shorter hospital stay, less post-procedure pain, minimal blood loss, and fewer complications. Local anesthesia additionally offers added advantage of awake and aware patients with immediate feedback of surgical decompression with minimal complications in experienced hands.

\section{Conflict of Interest}

None. 


\section{Disclaimer}

None.

\section{Bibliography}

1. Andersson GB. "Epidemiological features of chronic low-back pain". Lancet 354 (1999): 581-585.

2. Hussain SA., et al. "Cauda equina syndrome: outcome and implications for management". British Journal of Neurosurgery 17 (2003): 164-167.

3. Hoogland T., et al. "Endoscopic transforaminal discectomy for recurrent lumbar disc herniation: a prospective, cohort evaluation of 262 consecutive cases". Spine 33 (2008): 973-978.

4. Jha SC., et al. "Percutaneous endoscopic lumbar discectomy for a huge herniated disc causing acute cauda equina syndrome: a case report". Journal of Medical Investigation 62.1-2 (2015): 100-102.

5. Gardner A., et al. "Cauda equina syndrome: A review of the current clinical and medico-legal position". European Spine Journal 20.5 (2011): 690-697.

6. Anthony S. "Cauda equina syndrome". Medical Protection Society UK Casebook 20 (2000): 9-13.

7. Harrop JS., et al. "Conus medullaris and cauda equine syndrome as a result of traumatic injuries: management principles". Journal of Neurosurgery Focus 16 (2004): 19-23.

8. Ahn UM., et al. "Cauda equina syndrome secondary to lumbar disc herniation: a meta-analysis of surgical outcomes". Spine (Phila Pa 1976) 25.12 (2000): 1515-1522.

9. Gore S and Yeung A. "The "inside out" transforaminal technique to treat lumbar spinal pain in an awake and aware patient under local anesthesia: results and a review of the literature". International Journal of Spine Surgery 8 (2014).

10. Mahesha K. "Percutaneous endoscopic lumbar discectomy: Results of first 100 cases". Indian Journal of Orthopaedics 51.1 (2017): 36-42.

\section{Assets from publication with us}

- Prompt Acknowledgement after receiving the article

- Thorough Double blinded peer review

- Rapid Publication

- Issue of Publication Certificate

- High visibility of your Published work

Website: www.actascientific.com/

Submit Article: www.actascientific.com/submission.php

Email us: editor@actascientific.com

Contact us: +919182824667 